\title{
Quality and Storage Characteristics of Hot Press Tortilla Prepared from Yam-Wheat Composite Flour
}

\author{
Tawakalit Tope Asiyanbi-Hammed, Senay Simsek ${ }^{*}$ \\ Department of Plant Sciences, NDSU, Fargo, ND, USA \\ Email: *senay.simsek@ndsu.edu
}

How to cite this paper: Asiyanbi-Hammed, T.T. and Simsek, S. (2020) Quality and Storage Characteristics of Hot Press Tortilla Prepared from Yam-Wheat Composite Flour. Food and Nutrition Sciences, 11, 235-254.

https://doi.org/10.4236/fns.2020.114018

Received: February 28, 2020

Accepted: March 31, 2020

Published: April 3, 2020

Copyright $\odot 2020$ by author(s) and Scientific Research Publishing Inc. This work is licensed under the Creative Commons Attribution International License (CC BY 4.0).

http://creativecommons.org/licenses/by/4.0/

\begin{abstract}
Mixtures of refined wheat flour (RWF) with flours from different sources could impact the functional qualities and shelf life of wheat-based products. Storage stability is one of the most critical factors for tortilla quality. Tortillas made from yam (Dioscorea $s p$.) wheat composite flours were characterized. RWF was substituted with $5 \%, 10 \%, 15 \%$, and $20 \%$ of fermented yam flour-brown (FYF) and unfermented yam flour-white (UYF). Farinograph water absorptions of UYF-composite flours $(65.5 \%-77.1 \%)$ were significantly $(\mathrm{P}<0.05)$ higher than FYF-composite flour absorptions (60.5\% - 61.5\%). During storage, moisture contents of composite flour tortillas increased while the RWF-tortilla decreased. Tortilla from FYF-composite flour exhibited greater strength (3.1 $\mathrm{N}$ at day zero on average) compared to UYF-composite tortillas $(2.1 \mathrm{~N}$ at day zero on average), while UYF-composite flour tortillas had good extensibility and rollability properties. The properties and composition type and ratios of flour blends affected tortilla quality during the storage period. The substitution of RWF with $15 \%$ or $20 \%$ UYF would be more suitable for making tortilla with improved properties compared to that of FYF.
\end{abstract}

\section{Keywords}

Composite Flour, Specialty Crops, Fermented Yam, Unfermented Yam, Wheat

\section{Introduction}

A wheat flour tortilla is an unfermented flatbread, which is an essential staple food of consumers in Northern Mexico and the United States. Tortillas have become popular around the globe [1]. Tortilla sales in the United States have been increasing over the last decade, and as of 2015, the sale of tortilla totaled nearly 
$\$ 14$ billion US. Among the tortilla product sold in the United States, flour tortillas made up $43 \%$ of the market share in 2015 [2].

Similar to other wheat-based foods, wheat flour tortillas are rich in carbohydrates with a high glycemic index and low in minerals and fiber. Consumers are concerned about the health implications of foods such as wheat tortillas, and so there is an increased demand for tortillas with better nutritional value [1] [3] [4]. Ongoing research efforts have been initiated toward the improvement of nutritional profiles of wheat tortillas. Out of several methods under consideration, the production of tortillas from composite flour is a viable approach [1] [5], which is achieved by substitution of wheat flour with other flour to make healthier tortillas. Previous studies have shown that yam flours have higher mineral content, higher dietary fiber content, higher resistant starch content, and lower estimated glycemic index (eGI) than refined wheat flour [6] [7].

Yam belongs to the Dioscoreaceae family, and it is an annual plant with tuberous root, cordate leaves, and cylindrical. It is mostly grown in tropical and subtropical Africa, the Caribbean, South Pacific, and Asia [8]. Yam is very high in moisture; therefore, it is processed to dried flours with longer shelf life. Yam flour can be processed into either unfermented yam flour that is white in color or fermented yam flour that is brown. The color of the fermented yam flour is brown as the result of enzymatic browning reactions during fermentation due to the presence of water-soluble phenolic substances [8] [9].

Numerous composite flours have been formulated and investigated to develop food products with improved nutrition and functionalities. Composite flours have been used to increase dietary fiber content [10] [11] and to increase antioxidant and protein content [1] [3] of flour tortillas.

Another reason for the development of products using composite flours is the economic impact. Composite flour is of utmost benefit to developing countries as it promotes the exploration of some valuable native plant species, enhances the nutritional supply of protein, and promotes domestically grown products [12] [13] [14]. The development of suitable wheat-based composite flours has attracted considerable attention in developing countries, most notably for economic reasons. Numerous initiatives have been underway, including compulsory inclusion of $10 \%$ cassava flour into wheat flour for bread making, in Nigeria [15]. The Food and Agriculture Organization of the United Nations (FAO) in 1964 has equally proposed including cassava, yam, maize, and others to partially substitute wheat flour for temperate countries. It was further stated that the inclusion of domestic grown products into wheat for the production of confectionaries and bread would be of immense economic and nutritional advantages [16].

Some studies have been conducted on the use of wheat-yam composite flour for the production of bread, cake, and cookies [7] [17] [18]. However, there have not been any studies on the use of wheat-yam composite flours for the production of tortillas.

The substitution of wheat flour with other flours reportedly results in an alte- 
ration of the physicochemical properties of wheat flour [19] [20]. Prior study of physicochemical and end-product quality is required for the formulation of composite flour that will meet market acceptability. Composite flours can exhibit novel properties to achieve tailor-made product quality. Also, the freshness of tortilla during storage is one of the primary quality factors of great importance to the consumer. It is critical to evaluate how the addition of yam flours will impact tortilla texture and staling during storage. The main objective of this research work is to investigate the physicochemical properties of wheat-yam flour blends and the quality of the tortillas produced from the composite flours during storage (Graphical Abstract).

\section{Materials and Methods}

\subsection{Materials}

All the chemicals and reagents were of analytical grade. White unfermented yam flour (UYF) and brown fermented yam flour (FYF) used in this study were obtained at Oja Oba local market Ibadan, Oyo state in Nigeria. The fermentation process employed for the FYF was that which is traditionally done in Nigeria. This process involves peeling, washing, chipping, and conditioning the yam before a period of steeping in water (fermentation) for 24 hours before drying and milling [6]. The wheat flour used was hard red spring wheat (Triticum aestivum) patent flour, obtained from North Dakota Mill (Grand Forks, ND). The hard red spring wheat flour was substituted with the white or brown yam flours at $5 \%$, $10 \%, 15 \%$, and $20 \%(\mathrm{w} / \mathrm{w})$. In total, eight composite flours were produced and compared to the hard red spring wheat flour, as a control.

\subsection{Proximate Analysis of Flour Composition}

The composition of the wheat flour and composite flour blends was determined according to AACCI Approved Methods [21]. Moisture and ash contents of the flours were determined according to methods 44-15.02 and 08-01.01, respectively [21]. Protein content (14\% moisture basis, $\mathrm{mb}$ ) of each of the flours was determined by the combustion method using a LECO FP428 nitrogen analyzer (LECO Corporation, St. Joseph Michigan) according to method 46-30.01 [21]. Wet gluten and gluten index were determined according to method 38-12 [21] using an automatic gluten washing apparatus (Glutomatic $2200 \mathrm{~S}$ system, Perten Instruments, Springfield, IL, USA). The flour color was determined using a Minolta colorimeter to determine $\mathrm{L}^{\star}, \mathrm{a}^{\star}$, and $\mathrm{b}^{\star}$ values on the CIE Lab color scale.

\subsection{Pasting Profile of Wheat and Yam Flours}

Pasting properties of the flour samples were evaluated following the AACCI Approved method 76-21.01 [21] using a Rapid Visco analyzer (RVA, Perten instruments, Springfield, IL). The standard-1 heating and cooling profile was used to evaluate pasting viscosity [21]. 


\subsection{Farinograph Determination of Yam Flour Blends}

Rheological dough properties and dough strength of the flours were determined using a Farinograph (C.W. Brabender Instruments Inc., Hackensack, NJ) according to AACCI Approved Method 54-21.02 [21].

\subsection{Tortilla Preparation}

The formulation and production of the tortillas was performed following the method Whitney, et al. [22] with slight modification. The formulation of the tortillas included flour (100\%), water (90\% of the farinograph water absorption), table salt $(1.5 \%)$, vegetable shortening $(6 \%)$, sodium bicarbonate $(0.4 \%)$, sodium aluminum phosphate $(0.3 \%)$, sodium propionate $(0.4 \%)$, potassium sorbate $(0.4 \%)$, sodium stearoyl lactylate $(0.2 \%)$, diacetyl tartaric acid ester of mono- and diglycerides (DATEM) $(0.2 \%)$, and fumaric acid $(0.3 \%)$.

All ingredients were mixed to optimum consistency using a pin mixer with a 250 g capacity bowl (National Manufacturing Co., Lincoln, NE). The dough was rested for 10 minutes in a plastic bag. The dough was divided into $40 \mathrm{~g}$ pieces, hand rounded, rested for 15 minutes in a plastic bag. The dough was pressed on a CucinaPro Electric Tortilla Maker for 10 seconds. The tortillas were baked in a Baxter mini rotating rack oven (Baxter Mfg., Orting, WA) at $149^{\circ} \mathrm{C}$ until fully puffed (top and bottom layers had completely separated, but the edge had not broken open) [23]. Then, the tortillas were cooled on wire racks before packing into plastic zip-top bags. Tortillas were stored in sealed plastic bags for further analysis at room temperature $\left(\approx 22^{\circ} \mathrm{C}-24^{\circ} \mathrm{C}\right)$ for seven days after production. During the storage period, physical measurements of the tortillas were taken on days $0,1,2,5$, and 7 .

\subsection{Physical Measurement of Tortillas Characteristics}

Tortillas were evaluated for moisture content, weight, thickness, diameter, color, and rollability on days $0,1,2,5$, and 7 . The moisture of the fresh tortillas was performed according to AACCI Approved Method 44-15.02 [21]. The weight of a stack of five tortillas was taken, and the weight was divided by five to get the average weight of one tortilla. The thickness of five tortillas was measured with a caliper at three points and averaged and divided by five to get the average thickness of a single tortilla. The diameter was measured at the widest and most narrow points of three tortillas and then averaged. Rollability was measured following the method of Kelekci, et al. [24]. One tortilla was rolled around a 1.0-cm dowel and evaluated subjectively on a scale from 1 to 5 ( $1=$ unrollable, $2=$ breakage on two sides, 3 = breakage on one side, $4=$ slight cracking, $5=$ easily rollable). Tortilla extensibility and toughness were determined by measuring the force and distance to break a strip of the tortilla. The extensibility test was performed on a TA-TX2i Texture Analyzer (Texture Technologies Corp., Scarsdale, NY) according to the procedure of Suhendro, et al. [25]. Color of Tortilla was measured by light reflectance using a Minolta Color Difference Meter (Model 
CR410, Minolta Camera Co., Japan). The values were expressed using the CIE Lab color scale for $\mathrm{L}^{\star}, \mathrm{a}^{\star}$, and $\mathrm{b}^{*}$ values. Data for color are means of three replicate readings at different parts of the tortilla.

\subsection{Statistical Analysis}

Each treatment was prepared in duplicate. All measurements on the replicate batches of tortillas were also carried out in duplicate. The experimental data was subjected to statistical evaluation using analysis of variance (ANOVA) for a completely randomized design (CRD) using Statistical Analysis System (SAS Institute, Cary, NC, USA). Least significant difference was used to determine the difference among means, and the significance was defined at $\mathrm{P}<0.05$.

\section{Results and Discussion}

\subsection{Proximate Composition of Wheat Flour and Wheat/Yam Flour Blends}

The proximate composition and color of RWF and flour blends are shown in Table 1 and were significantly $(\mathrm{P}<0.05)$ different among the different composite flours. The compositions of the UYF and FYF were found to be typical for unfermented and fermented yam flours [26]. The protein, ash, and starch contents of the UYF flour were 5.9\%, 2.2\%, and 73.8\% (dry weight basis), respectively. The protein, ash, and starch contents of the FYF flour were $3.3 \%, 1.7 \%$, and $74.2 \%$ (dry weight basis), respectively. The composite flour compositions ranged from $10.2 \%-12.3 \%$ for protein, $0.39 \%-0.77 \%$ for ash, $25.9 \%-35.2 \%$ for wet gluten, and 72 - 93 for gluten index. An increase in the concentration of UYF and FYF in flour blends caused a reduction in protein content. The reduction of protein content is due to dilution of the protein from the RWF with the

Table 1. Proximate composition of wheat flour and wheat/yam flour blends.

\begin{tabular}{ccccccccc}
\hline Sample & Moisture & Protein & Ash & Wet gluten & Gluten & \multicolumn{3}{c}{ Color } \\
\hline RWF & $13.8 \mathrm{a}$ & $12.3 \mathrm{a}$ & $0.39 \mathrm{~g}$ & $32.7 \mathrm{bc}$ & $89 \mathrm{a}$ & $89.93 \mathrm{a}$ & $-0.63 \mathrm{e}$ & $9.34 \mathrm{e}$ \\
$5 \%$ UYF & $13.7 \mathrm{~b}$ & $11.8 \mathrm{~b}$ & $0.47 \mathrm{e}$ & $32.3 \mathrm{bc}$ & $93 \mathrm{a}$ & $89.68 \mathrm{~d}$ & $-0.65 \mathrm{f}$ & $9.42 \mathrm{~d}$ \\
$10 \%$ UYF & $13.6 \mathrm{c}$ & $11.5 \mathrm{c}$ & $0.53 \mathrm{~d}$ & $34.2 \mathrm{ab}$ & $92 \mathrm{a}$ & $89.80 \mathrm{c}$ & $-0.69 \mathrm{~g}$ & $9.46 \mathrm{~cd}$ \\
$15 \%$ UYF & $13.3 \mathrm{~d}$ & $11.3 \mathrm{c}$ & $0.60 \mathrm{bc}$ & $33.5 \mathrm{ab}$ & $86 \mathrm{a}$ & $89.88 \mathrm{~b}$ & $-0.74 \mathrm{~h}$ & $9.63 \mathrm{~b}$ \\
$20 \%$ UYF & $13.2 \mathrm{~d}$ & $10.9 \mathrm{~d}$ & $0.61 \mathrm{~b}$ & $35.2 \mathrm{a}$ & $72 \mathrm{~b}$ & $89.72 \mathrm{~d}$ & $-0.76 \mathrm{~h}$ & $9.78 \mathrm{a}$ \\
$5 \%$ FYF & $13.8 \mathrm{a}$ & $11.8 \mathrm{~b}$ & $0.42 \mathrm{f}$ & $30.9 \mathrm{~cd}$ & $89 \mathrm{a}$ & $88.66 \mathrm{e}$ & $-0.12 \mathrm{~d}$ & $9.15 \mathrm{~g}$ \\
$10 \%$ FYF & $13.7 \mathrm{~b}$ & $11.3 \mathrm{c}$ & $0.49 \mathrm{e}$ & $30.0 \mathrm{ed}$ & $91 \mathrm{a}$ & $87.34 \mathrm{f}$ & $0.33 \mathrm{c}$ & $9.47 \mathrm{c}$ \\
$15 \%$ FYF & $13.7 \mathrm{~b}$ & $10.8 \mathrm{~d}$ & $0.58 \mathrm{c}$ & $28.1 \mathrm{e}$ & $89 \mathrm{a}$ & $86.68 \mathrm{~g}$ & $0.62 \mathrm{~b}$ & $9.30 \mathrm{f}$ \\
$20 \%$ FYF & $13.5 \mathrm{c}$ & $10.2 \mathrm{e}$ & $0.77 \mathrm{a}$ & $25.9 \mathrm{f}$ & $91 \mathrm{a}$ & $85.85 \mathrm{~h}$ & $0.86 \mathrm{a}$ & $9.46 \mathrm{c}$ \\
\hline
\end{tabular}

${ }^{\dagger}$ Protein, ash and wet gluten are presented on a $14 \%$ moisture basis. Values in the same column with the same letter are not statistically significant $(\mathrm{P}<0.05), \mathrm{RWF}=$ refined wheat flour, UYF $=$ unfermented-white yam flour, FYF = fermented-brown yam flour. 
yam flours that have lower protein contents. Yam flours do not contain gluten, so the gluten is further diluted by the addition of UYF and FYF. The differences in gluten content and gluten index may also be impacted by enzymes that may be present in the FYF. These enzymes and other compounds from the yam flours could impact the extractability and disturb the gluten network during the gluten washing process. The increase in the concentration of UYF and FYF in the flour blends leads to an increase in ash content, which would increase the nutritional value of the tortillas by increasing mineral content. The addition of 5 to 20 UYF did not significantly $(\mathrm{P}<0.05)$ effect the gluten content. However, 20\% UYF had a significant $(\mathrm{P}<0.05)$ impact on gluten quality, as is reflected in the change in gluten index values. For the FYF blends, significant $(\mathrm{P}<0.05)$ reduction in wet gluten occurred with an increase in FYF concentration, but no change in gluten index was observed. The wheat protein fractions have been reported to play an essential role in wheat flour properties, most notably the tortilla quality [27].

The color of the composite flours ranged from $85.85-89.93,-0.65-0.86$, and 9.30 - 9.78, respectively, for brightness $\left(L^{*}\right)$, redness $\left(a^{*}\right)$ and yellowness $\left(b^{*}\right)$. All composite flours had significantly $(\mathrm{P}<0.05)$ lower $\mathrm{L}^{\star}$ values than the RWF; however, only the composites with FYF differed visually from the RWF. Upon increase in concentration FYF in composite flours, $\mathrm{a}^{*}$ values increased significantly $(\mathrm{P}<0.05)$, indicating increased redness in flour composites with FYF. Increasing yam flour, especially FYF, the concentration decreased whiteness of flour blends. The differences in the color of the yam flours are caused by the two different processing methods to produce them and the reactions that occur during the fermentation process of the fermented yam [28]. The color of the FYF is caused by discoloration associated with enzymatic browning from the action of polyphenol oxidase (PPO) and peroxidase, which lead to the production of phenolic compounds. The UYF is blanched prior to further processing, which inactivates the enzymes that lead to color formation [29].

\subsection{Pasting Profile of Wheat/Yam Flour Blends}

Table 2 shows the pasting profiles of the flour samples, which provides information about the gelatinization properties of the flour during heat processing. During the heat processing of tortilla, the gluten network traps steam and starch granules are partially gelatinized near the surface. Then as heating continues, gelatinization occurs in the center of the tortilla. After that, the gluten network is then fully formed; amylose has leached out of the granules resulting in full gelatinization of starch granules. After the tortillas are baked, the starch immediately begins to retrograde. The amylose and amylopectin complex together form a matrix that stiffens the tortilla [30].

There were significant $(\mathrm{P}<0.05)$ differences in the pasting properties of the composite blends. The peak viscosity (PV), hot past viscosity (HPV), breakdown, final viscosity (FV), setback, peak time and pasting temperature ranged between 1219 - $1596 \mathrm{cP}, 474-644 \mathrm{cP}, 641$ - $952 \mathrm{cP}, 1131$ - $1498 \mathrm{cP}, 658$ - $854 \mathrm{cP}$, $5.47-5.70$ minutes and $69.8^{\circ} \mathrm{C}-84.0^{\circ} \mathrm{C}$, respectively. Except for peak time, all 
Table 2. Pasting profile of wheat/yam flour blends.

\begin{tabular}{cccccccc}
\hline & PV & HPV & Breakdown & FV & Setback & $\begin{array}{c}\text { Peak } \\
\text { Time }\end{array}$ & $\begin{array}{c}\text { Pasting } \\
\text { Temperature }\end{array}$ \\
\hline RWF & $1353 \mathrm{bc}$ & $486 \mathrm{c}$ & $868 \mathrm{c}$ & $1168 \mathrm{c}$ & $683 \mathrm{~b}$ & $5.57 \mathrm{bc}$ & $69.8 \mathrm{~b}$ \\
$5 \%$ UYF & $1290 \mathrm{bcd}$ & $474 \mathrm{c}$ & $817 \mathrm{~d}$ & $1131 \mathrm{c}$ & $658 \mathrm{~b}$ & $5.60 \mathrm{ab}$ & $70.2 \mathrm{~b}$ \\
$10 \%$ UYF & $1277 \mathrm{~cd}$ & $500 \mathrm{c}$ & $778 \mathrm{de}$ & $1171 \mathrm{c}$ & $672 \mathrm{~b}$ & $5.60 \mathrm{ab}$ & $69.8 \mathrm{~b}$ \\
$15 \%$ UYF & $1271 \mathrm{~cd}$ & $538 \mathrm{bc}$ & $733 \mathrm{e}$ & $1219 \mathrm{c}$ & $681 \mathrm{~b}$ & $5.63 \mathrm{ab}$ & $70.2 \mathrm{~b}$ \\
$20 \%$ UYF & $1219 \mathrm{~d}$ & $578 \mathrm{ab}$ & $641 \mathrm{f}$ & $1250 \mathrm{bc}$ & $672 \mathrm{~b}$ & $5.70 \mathrm{a}$ & $70.2 \mathrm{~b}$ \\
$5 \%$ FYF & $1394 \mathrm{~b}$ & $492 \mathrm{c}$ & $902 \mathrm{bc}$ & $1196 \mathrm{c}$ & $704 \mathrm{~b}$ & $5.47 \mathrm{c}$ & $84.0 \mathrm{a}$ \\
$10 \%$ FYF & $1515 \mathrm{a}$ & $579 \mathrm{ab}$ & $936 \mathrm{ab}$ & $1379 \mathrm{ab}$ & $800 \mathrm{a}$ & $5.53 \mathrm{bc}$ & $83.6 \mathrm{a}$ \\
$15 \%$ FYF & $1580 \mathrm{a}$ & $642 \mathrm{a}$ & $938 \mathrm{ab}$ & $1493 \mathrm{a}$ & $851 \mathrm{a}$ & $5.53 \mathrm{bc}$ & $83.2 \mathrm{a}$ \\
$20 \%$ FYF & $1596 \mathrm{a}$ & $644 \mathrm{a}$ & $952 \mathrm{a}$ & $1498 \mathrm{a}$ & $854 \mathrm{a}$ & $5.53 \mathrm{bc}$ & $83.2 \mathrm{a}$ \\
\hline
\end{tabular}

${ }^{\dagger}$ Values in the same column with the same letter are not statistically significant $(\mathrm{P}<0.05)$; $\mathrm{PV}=$ peak viscosity, $\mathrm{HPV}=$ hot paste viscosity, $\mathrm{FV}=$ final viscosity, RWF $=$ refined wheat flour, UYF $=$ unfermented-white yam flour, FYF = fermented-brown yam flour.

pasting properties of FYF composite blends are higher than that of UYF of the same concentration. The peak time increased as the concentration of UYF increased but decreased as the concentration of FYF increased in the composite blends. All composite blends containing FYF exhibited higher PV and breakdown values than that of RWF. The high PV with short peak time duration in FYF signifies peak viscosity is reached more quickly, due to more rapid swelling of starch granules. Likewise, the higher breakdown value is anticipated due to higher viscosity, which causes the granule to collapse easily because of weak intermolecular forces among starch molecules due to increased sensitivity to shear forces [31]. This suggests that FYF blends are more highly susceptible to shear and heat than the control and UYF composites. The results agreed with the previous reports stating that an increase in fiber content caused a decrease in PV [32]. So, it could be inferred from the result that UYF may withstand heat and shear stress better than the control. The HPV and FV values of all composite flours, except those of 5\% UYF, are higher than RWF, and an increase in the concentration of UYF and FYF in composite flours resulted in an increase in their HPV and FV values. Setback from peak, which indicates firmness of samples ranged from $657.5-853.5 \mathrm{cP}$. Statistical analysis revealed no significant $(\mathrm{P}<$ 0.05 ) difference in the control and the UYF. For the blends, setback increased as the concentration of FYF increased but lacked a specific trend for UYF. This suggests that FYF with higher setback may exhibit firmer gel suggesting fast retrogradation and high syneresis. Thus, UYF with lower setback was expected to be more resistant to retrogradation than FYF with a higher amylose amount. This is because amylose readily diffuses out of starch granules during gelatinization and rapidly recrystallizes when it cools after gelatinization [33]. The pasting temperature of composite flours decreased as the concentration of FYF increased 
but lacked specific trends as the concentration of UYF increased. The pasting temperature for FYF is significantly higher than the control and UYF. The result implied that the minimum temperature required to initiate the gelatinization process for FYF exceeds that of UYF. Thus, more energy cost and formula stability will be needed than that of its counterpart. Overall, tortillas made with FYF are expected to retrograde fastest, and those made with UYF are projected to have the same storage shelf life as that of the control.

\subsection{Dough Quality Measured by Farinograph of Wheat/Yam Flour Blends}

All the farinograph dough quality measurements, shown in Table 3, are significantly $(\mathrm{P}<0.05)$ different among the composite flour samples. Water absorption, peak time, stability, mixing tolerance index (MTI), and farinograph quality number (FQN) ranged from $60.50 \%-77.10 \%(14 \% \mathrm{MB}), 1.85-6.75$ minutes, 3.50 - 13.65 minutes, $17.0-135.5 \mathrm{BU}$ and $28.5-117.5 \mathrm{~mm}$, respectively. UYF blends have significantly $(\mathrm{P}<0.05)$ higher water absorption and MTI than FYF and control. An increase in the concentration of UYF in composite flours caused an increase in water absorption and MTI. The higher water absorptions value of UYF is attributed to its higher level of starch damage and fiber contribution. The UYF had $18.1 \%$ starch damage, and $6.8 \%$ total dietary fiber, and the FYF had $3.0 \%$ starch damage and $7.0 \%$ total dietary fiber [26]. Typical values for starch damage and dietary fiber for refined wheat flour are around $7 \%$ and $4 \%$, respectively [26]. The higher water absorptions value of UYF is attributed to its higher level of starch damage and fiber contribution. This result is in agreement with a previous report that found an increase in cellulose fiber caused an increase in water absorption of dough [32]. Also, the starch damage of the UYF flour is much higher than starch damage for wheat flours [26]. It is likely that the fermentation

Table 3. Dough quality measured by farinograph of wheat/yam flour blends.

\begin{tabular}{cccccc}
\hline & \% Water Absorption & Peak time & Stability & MTI & FQN \\
\hline RWF & $(14 \% \mathrm{MB})$ & $(\mathrm{min})$ & $(\mathrm{min})$ & $(\mathrm{BU})$ & $(\mathrm{mm})$ \\
\hline 5 UYF & $62.4 \mathrm{e}$ & $6.8 \mathrm{a}$ & $13.7 \mathrm{a}$ & $26.5 \mathrm{c}$ & $118 \mathrm{a}$ \\
$10 \% \mathrm{UYF}$ & $65.5 \mathrm{~d}$ & $3.9 \mathrm{~b}$ & $6.9 \mathrm{~d}$ & $58.0 \mathrm{bc}$ & $70 \mathrm{bc}$ \\
$15 \%$ UYF & $69.8 \mathrm{c}$ & $2.8 \mathrm{bcd}$ & $4.4 \mathrm{e}$ & $94.0 \mathrm{ab}$ & $48 \mathrm{~cd}$ \\
$20 \% \mathrm{UYF}$ & $74.1 \mathrm{~b}$ & $3.2 \mathrm{bc}$ & $3.5 \mathrm{e}$ & $118.0 \mathrm{a}$ & $46 \mathrm{~cd}$ \\
$5 \% \mathrm{FYF}$ & $77.1 \mathrm{a}$ & $3.8 \mathrm{~b}$ & $3.9 \mathrm{e}$ & $135.5 \mathrm{a}$ & $49 \mathrm{~cd}$ \\
$10 \% \mathrm{FYF}$ & $61.5 \mathrm{ef}$ & $6.6 \mathrm{a}$ & $12.8 \mathrm{a}$ & $33.0 \mathrm{c}$ & $110 \mathrm{a}$ \\
$15 \% \mathrm{FYF}$ & $61.0 \mathrm{f}$ & $2.1 \mathrm{~cd}$ & $9.8 \mathrm{~b}$ & $17.0 \mathrm{c}$ & $88 \mathrm{ab}$ \\
$20 \% \mathrm{FYF}$ & $60.5 \mathrm{f}$ & $1.9 \mathrm{~d}$ & $8.6 \mathrm{bc}$ & $30.0 \mathrm{c}$ & $54 \mathrm{~cd}$ \\
\hline
\end{tabular}

${ }^{\dagger}$ Values in the same column with the same letter are not statistically significant $(\mathrm{P}<0.05)$; $\mathrm{MB}=$ moisture basis, $\mathrm{MTI}=$ mixing tolerance index, $\mathrm{FQN}=$ farinograph quality number, $\mathrm{RWF}=$ refined wheat flour, UYF $=$ unfermented-white yam flour, FYF $=$ fermented-brown yam flour. 
of the yams during the production of FYF resulted in an increase in starch damage. The fermentation may have resulted in some hydrolysis of the starch granules. The damaged starch will absorb water where the undamaged starch will not absorb water at room temperature. Thus, the high percentage of starch damage in the FYF is likely a significant factor in the increased farinograph water absorption [34].

Although the increase in the concentration of FYF in the composite flour caused a decrease in water absorption, there was not significant $(\mathrm{P}<0.05)$ difference. The peak times for the blends of UYF and FYF are lower than the control, thus, implying that more time is needed to mix the dough to maximum consistency in the control sample than the blended samples. An increase in the concentration of FYF in composite flour resulted in a decrease in peak time, stability, and FQN. The FYF composite flours have longer stability than that of UYF composite flours, but not than that of the control.

The quality of dough will have significant effects on processing parameters and the final quality of tortillas. Generally, high water absorption, as was obtained for $15 \%$ UYF and 20\% UYF, is desirable for processors. Since dough with higher absorption will contain more water, a relatively low-cost ingredient compared to flour. Processors would also require a certain level of mixing tolerance, indicated by the stability value. FYF had a lower effect on stability than the addition of UYF. Therefore, processors would have to take more care during the mixing of tortilla dough containing UYF. The lower peak time of dough with UYF and FYF may be beneficial to processors since less time and energy would need to be expended to mix the dough.

\subsection{Physical Characteristics of Tortillas Made from Wheat/Yam Flour Blends}

In any food product, there is a demand for consistency in order to maintain established processing parameters. Therefore, physical characteristics need to be measured to ensure consistency and identification of adverse effects due to formulation and processing change. During the production of the yam/wheat flour tortillas, the dough handling for all samples was equally good. High water absorption sometimes causes problems in machinability and dough handling. However, the dough of UYF and FYF tortillas was moist but smooth and not sticky. The composition of flour has an impact on the weight and physical characteristics of wheat flour tortillas. Inclusion of yam flour seemed to greatly affect the products, creating tortillas that were smaller, thicker, and heavier. Table 4 shows the physical characteristics (weight, diameter, and thickness) of tortillas made from RWF, FYF, and UYF. Statistical analysis shows there were significant $(\mathrm{P}<0.05)$ differences in all the samples. The weight of the tortillas ranged between 33.04 - $36.69 \mathrm{~g}$, tortilla diameter ranged between $146.33-157.17 \mathrm{~mm}$, and the thickness of tortillas ranged from $3.29-2.75 \mathrm{~mm}$.

All tortillas made from composite flours are of higher thickness than that of RWF, except that of $20 \%$ UYF. An increase in the concentration of UYF in 
Table 4. Physical characteristics of tortillas made from wheat/yam flour blends.

\begin{tabular}{cccc}
\hline & Weight & Diameter & Thickness \\
\hline RWF & $\mathrm{g}$ & $\mathrm{mm}$ & $\mathrm{mm}$ \\
\hline $5 \%$ UYF & $33.0 \mathrm{e}$ & $157.2 \mathrm{a}$ & $2.8 \mathrm{~d}$ \\
$10 \%$ UYF & $34.7 \mathrm{bcd}$ & $154.5 \mathrm{ab}$ & $3.0 \mathrm{bc}$ \\
$15 \%$ UYF & $34.5 \mathrm{cde}$ & $150.2 \mathrm{bcd}$ & $3.0 \mathrm{bc}$ \\
$20 \%$ UYF & $33.8 \mathrm{de}$ & $147.7 \mathrm{~cd}$ & $2.9 \mathrm{c}$ \\
$5 \%$ FYF & $34.3 \mathrm{cde}$ & $149.2 \mathrm{bcd}$ & $2.6 \mathrm{e}$ \\
$10 \%$ FYF & $33.8 \mathrm{de}$ & $152.7 \mathrm{abc}$ & $2.9 \mathrm{~cd}$ \\
$15 \%$ FYF & $36.7 \mathrm{a}$ & $146.3 \mathrm{~d}$ & $3.2 \mathrm{ab}$ \\
$20 \% \mathrm{FYF}$ & $36.1 \mathrm{ab}$ & $144.3 \mathrm{~d}$ & $3.3 \mathrm{a}$ \\
\hline
\end{tabular}

${ }^{\dagger}$ Values in the same column with the same letter are not statistically significant $(\mathrm{P}<0.05)$; RWF $=$ refined wheat flour, UYF = unfermented-white yam flour, FYF = fermented-brown yam flour.

composite flours resulted in a decrease in the diameter and thickness of tortillas. An increase in the concentration of FYF in composite flours increased thickness but lacked a specific trend for weight and diameter of tortillas, and the inclusion of $5 \%$ and $10 \%$ of UYF lacked a significant effect on tortillas diameter and weight, respectively.

In a comparative study of whole and refined wheat flour, tortillas made from whole-wheat flour were reported to be larger, less opaque, and thinner compared to refined flour tortillas. It was explained that the difference in whole and refined wheat tortillas were because high fiber caused a dilution effect on the gluten content, consequently effecting the size, thickness, and texture, which decreased the tortilla quality of whole-wheat tortillas [5]. In the US, many consumers prefer fluffy, thick, and opaque tortillas [35]. In this regard, tortilla samples from UYF are a better fit than the FYF tortillas. Compared to control, the diameter of tortillas prepared from UYF and FYF composite flours is smaller. So, these tortillas might not be able to hold as much filling as the RWF tortillas. Because of this, processors may have to scale out larger dough pieces or modify the formulation to make tortillas of the same diameter. This might add additional cost to producers, but more investigation would be needed to determine the costs associated with replacing wheat flour with yam flour in tortillas.

\subsection{Effect of Storage on the Color of Tortillas}

The storability of tortillas is very important to the food industry as well as the consumer. From an industrial perspective, tortillas must be able to keep its freshness from the production point until it reaches the consumer to be acceptable. Also, it is economical that consumers can keep products for some time to reduce the frequency of going to stores as well as reduce waste. The addition of new ingredients to tortillas flour has an impact on the shelf life of tortillas and 
requires adequate investigation. Inclusion of non-wheat flour into RWF should not cause a significant effect on tortillas quality attributes, including color changes during storage.

Table 5 shows the color of tortillas during seven days of storage. The color of the tortillas was significantly different among the samples. The brightness $\left(L^{\star}\right)$, of tortillas made from all of the composite flours, decreased during storage. Comparing days zero and seven, significant $(\mathrm{P}<0.05)$ differences were only determined for the yellowness of the tortillas made from all FYF flours, and the 5\% and $15 \%$ UYF flours. In terms of redness, FYF flour resulted in higher values than that of UYF, even throughout the storage period. A higher concentration of FYF in composite intensified redness of tortillas, and the redness attribute was maintained after seven days of storage. The color of the tortillas made from the composite flours was affected by the presence of yam flour. During yam flour production, yams can become discolored due to their polyphenol content and the presence of PPO and peroxidase. The discoloration of the yams during fermentation results in a brown-colored flour [28] [29]. The redness of the tortillas with FYF may be attributed to the phenolic content, PPO, or peroxidase content of the flours. In the case of the flours used in this study, the FYF has clearly undergone a color change during its processing, resulting in the brown color of the

Table 5. Color of tortillas made from wheat/yam flour blends during seven days of storage.

\begin{tabular}{ccccccccccc}
\hline & & & $5 \%$ & $10 \%$ & $15 \%$ & $20 \%$ & $5 \%$ & $10 \%$ & $15 \%$ & $20 \%$ \\
& & RWF & UYF & UYF & UYF & UYF & FYF & FYF & FYF & FYF \\
\hline & $\mathrm{L}^{*}$ & $79.78 \mathrm{a}$ & $77.73 \mathrm{ab}$ & $76.95 \mathrm{ab}$ & $76.50 \mathrm{~b}$ & $76.38 \mathrm{~b}$ & $75.99 \mathrm{~b}$ & $69.16 \mathrm{c}$ & $67.67 \mathrm{c}$ & $63.36 \mathrm{~d}$ \\
Day 0 & $\mathrm{a}^{*}$ & $0.26 \mathrm{e}$ & $0.42 \mathrm{e}$ & $0.09 \mathrm{ef}$ & $-0.36 \mathrm{fg}$ & $-0.56 \mathrm{~g}$ & $1.98 \mathrm{~d}$ & $3.33 \mathrm{c}$ & $3.93 \mathrm{~b}$ & $4.91 \mathrm{a}$ \\
& $\mathrm{b}^{*}$ & $18.09 \mathrm{bc}$ & $20.34 \mathrm{ab}$ & $21.97 \mathrm{a}$ & $22.37 \mathrm{a}$ & $22.77 \mathrm{a}$ & $18.44 \mathrm{~b}$ & $18.61 \mathrm{bc}$ & $17.51 \mathrm{bc}$ & $17.45 \mathrm{c}$ \\
& $\mathrm{L}^{*}$ & $78.34 \mathrm{a}$ & $77.60 \mathrm{a}$ & $77.44 \mathrm{a}$ & $77.94 \mathrm{a}$ & $76.95 \mathrm{a}$ & $73.46 \mathrm{~b}$ & $69.93 \mathrm{c}$ & $66.70 \mathrm{~d}$ & $63.36 \mathrm{e}$ \\
Day 1 & $\mathrm{a}^{*}$ & $0.15 \mathrm{e}$ & $0.21 \mathrm{e}$ & $-0.01 \mathrm{ef}$ & $-0.29 \mathrm{ef}$ & $-0.55 \mathrm{f}$ & $2.30 \mathrm{~d}$ & $3.35 \mathrm{c}$ & $4.13 \mathrm{~b}$ & $5.05 \mathrm{a}$ \\
& $\mathrm{b}^{*}$ & $21.13 \mathrm{ab}$ & $21.01 \mathrm{ab}$ & $22.21 \mathrm{a}$ & $21.59 \mathrm{ab}$ & $22.31 \mathrm{a}$ & $20.20 \mathrm{ab}$ & $19.43 \mathrm{bc}$ & $17.35 \mathrm{c}$ & $17.44 \mathrm{c}$ \\
& $\mathrm{L}^{*}$ & $77.32 \mathrm{bc}$ & $78.89 \mathrm{a}$ & $77.60 \mathrm{~b}$ & $78.49 \mathrm{ab}$ & $76.39 \mathrm{c}$ & $73.46 \mathrm{~d}$ & $68.60 \mathrm{e}$ & $67.14 \mathrm{f}$ & $63.21 \mathrm{~g}$ \\
Day 2 & $\mathrm{a}^{*}$ & $0.41 \mathrm{e}$ & $-0.18 \mathrm{f}$ & $-0.23 \mathrm{f}$ & $-0.52 \mathrm{f}$ & $-0.52 \mathrm{f}$ & $2.34 \mathrm{~d}$ & $3.48 \mathrm{c}$ & $4.02 \mathrm{~b}$ & $5.06 \mathrm{a}$ \\
& $\mathrm{b}^{*}$ & $21.55 \mathrm{~b}$ & $20.76 \mathrm{bc}$ & $22.52 \mathrm{ab}$ & $20.74 \mathrm{bc}$ & $23.54 \mathrm{a}$ & $19.67 \mathrm{~cd}$ & $18.43 \mathrm{de}$ & $17.28 \mathrm{e}$ & $17.50 \mathrm{e}$ \\
& $\mathrm{L}^{*}$ & $78.33 \mathrm{a}$ & $78.38 \mathrm{a}$ & $76.82 \mathrm{bc}$ & $77.40 \mathrm{ab}$ & $75.95 \mathrm{c}$ & $73.84 \mathrm{~d}$ & $68.63 \mathrm{e}$ & $67.20 \mathrm{f}$ & $64.26 \mathrm{~g}$ \\
Day 5 & $\mathrm{a}^{*}$ & $0.01 \mathrm{~d}$ & $-0.06 \mathrm{~d}$ & $-0.20 \mathrm{~d}$ & $-0.57 \mathrm{e}$ & $-0.23 \mathrm{de}$ & $2.07 \mathrm{c}$ & $3.84 \mathrm{~b}$ & $4.14 \mathrm{~b}$ & $4.71 \mathrm{a}$ \\
& $\mathrm{b}^{*}$ & $21.00 \mathrm{c}$ & $20.91 \mathrm{c}$ & $22.85 \mathrm{ab}$ & $21.40 \mathrm{bc}$ & $23.31 \mathrm{a}$ & $20.08 \mathrm{c}$ & $20.33 \mathrm{c}$ & $17.67 \mathrm{~d}$ & $17.09 \mathrm{~d}$ \\
& $\mathrm{~L}^{*}$ & $77.84 \mathrm{ab}$ & $78.34 \mathrm{a}$ & $76.60 \mathrm{ab}$ & $77.29 \mathrm{ab}$ & $75.96 \mathrm{~b}$ & $72.89 \mathrm{c}$ & $68.51 \mathrm{~d}$ & $68.23 \mathrm{~d}$ & $63.88 \mathrm{e}$ \\
Day 7 & $\mathrm{a}^{*}$ & $0.12 \mathrm{~d}$ & $0.04 \mathrm{de}$ & $0.08 \mathrm{~d}$ & $-0.15 \mathrm{de}$ & $-0.49 \mathrm{e}$ & $2.38 \mathrm{c}$ & $3.72 \mathrm{~b}$ & $4.17 \mathrm{~b}$ & $4.95 \mathrm{a}$ \\
& $\mathrm{b}^{*}$ & $20.83 \mathrm{bc}$ & $20.70 \mathrm{c}$ & $22.65 \mathrm{ab}$ & $21.52 \mathrm{bc}$ & $23.44 \mathrm{a}$ & $19.85 \mathrm{~cd}$ & $18.09 \mathrm{de}$ & $17.81 \mathrm{e}$ & $16.92 \mathrm{e}$ \\
\hline
\end{tabular}

${ }^{\dagger}$ Values in the same row with the same letter are not statistically significant $(\mathrm{P}<0.05)$; RWF $=$ refined wheat flour, UYF $=$ unfermented-white yam flour, FYF $=$ fermented-brown yam flour, $\mathrm{L}^{*}=$ brightness; $\mathrm{a}^{*}=$ redness; $\mathrm{b}^{\star}=$ yellowness. 
FYF flour. UYF did not have any PPO activity, while a small amount of PPO was detected in FYF [26]. The traditional definition of a good tortilla is one that has a uniform satiny white appearance with few browned spots. However, there are tortillas made with whole-grain flours or ingredients such as spinach that alter their color. Many consumers have accepted tortillas with different colors. The dark shade of red color in the FYF tortilla samples may be unappealing to a few consumers who prefer flour tortillas made from refined wheat flour. However, consumers who regularly consume whole wheat or spinach tortillas may not be bothered by the difference in color between RWF tortillas and tortilla containing FYF.

\subsection{Effect of Storage on the Moisture Content of Tortillas}

The moisture content in food products is an important parameter that influences shelf-life stability, textural characteristics, and mouthfeel. When properly packaged and stored, the moisture content of commercial tortillas may not change much until after the tortillas are purchased, and the consumer opens the package. However, the consumer may not use an entire package of tortillas at one time, resulting in the remaining tortillas being stored in a non-airtight container which may be opened multiple times. For this reason, it was essential to evaluate changes in the moisture of tortillas during storage. The moisture content of the tortillas during seven days of storage is presented in Figure 1. Statistically, there were significant $(\mathrm{P}<0.05)$ differences between the moisture content of the tortilla's samples. The moisture content of the tortillas made from RWF decreases gradually during the storage period. Inclusion of yam flours altered the sorption behavior of the tortillas made from composite flours compared to that of RWF. Inclusion of 5\% and 10\% of UYF caused high moisture content initially,

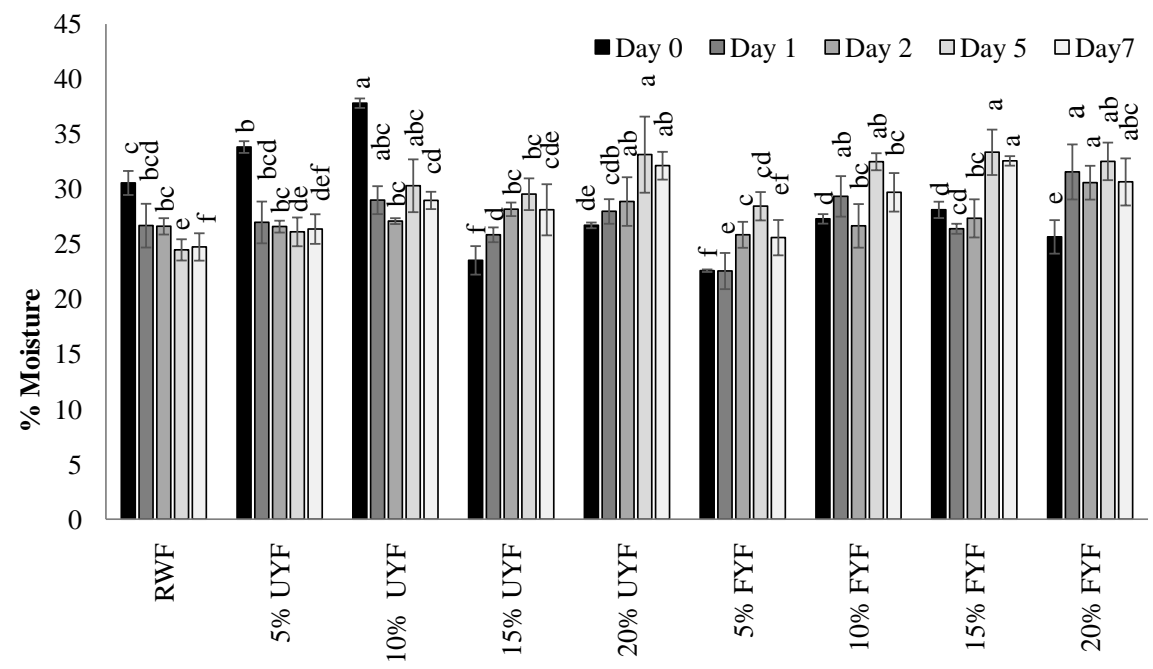

Figure 1. Moisture content of tortillas made from wheat/yam flour blends during seven days of storage. ${ }^{*}$ Bars of the same color with the same letter are not statistically significant $(\mathrm{P}<0.05) ; \mathrm{RWF}=$ refined wheat flour, $\mathrm{UYF}=$ unfermented-white yam flour, $\mathrm{FYF}=$ fermented-brown yam flour. 
which then reduced as the storage period increased. This observation can be related to their initial high water absorption and thickness that might be responsible for the reduction in dehydration rate during the baking process [5]. The moisture content of wheat flour tortillas typically ranges from 30\% - 32\% [36], which is near or slightly above the moisture content of most of the tortillas in this study.

The moisture sorption behavior of tortillas from other composite flours followed increasing trends throughout the storage period. The observation might be due to the high absorption rate of the composite flour. The increase in yam flour inclusion, which results in weight increase (Table 4), might be responsible for the retention of moisture.

\subsection{Effect of Storage on Rollability of Tortillas}

The rollability is a measure of the ability of tortillas to fold without breaking. The results of rollability testing are shown in Table 6 and are significantly $(\mathrm{P}<$ 0.05) different after day 0 . All samples exhibited good rollability and were not significantly $(\mathrm{P}<0.05)$ different among the different composite flour types at day 0 . In all samples, the rollability of tortillas decreased as the number of days increased. Rollability was significantly affected by differences in formulation and storage time. It has been found that thickness can hinder rollability and the rollability score was lower for thicker tortillas [37]. However, this finding is contrary to the result of our study. Composite yam flour inclusion resulted in a thicker tortilla, but the thickness did not interfere with the rollability. All the tortillas made with composite flour are thicker than the control; however, they exhibited better rollability than the control.

Their rollability could differentiate freshly made tortillas (day 0) from 1-day-old

Table 6. Rollability of tortillas made from wheat/yam flour blends during seven days of storage.

\begin{tabular}{cccccc}
\hline \multicolumn{5}{c}{ Rollability (Score of 1 - 5) } \\
\hline Day 0 & Day 1 & Day 2 & Day 5 & Day 7 \\
\hline RWF & $5.0 \mathrm{a}$ & $4.7 \mathrm{abc}$ & $3.3 \mathrm{~b}$ & $2.3 \mathrm{~d}$ & $1.3 \mathrm{f}$ \\
$5 \%$ UYF & $5.0 \mathrm{a}$ & $5.0 \mathrm{a}$ & $4.2 \mathrm{a}$ & $2.2 \mathrm{de}$ & $1.7 \mathrm{ef}$ \\
$10 \%$ UYF & $5.0 \mathrm{a}$ & $4.7 \mathrm{abc}$ & $4.3 \mathrm{a}$ & $3.3 \mathrm{~b}$ & $2.7 \mathrm{~b}$ \\
$15 \%$ UYF & $5.0 \mathrm{a}$ & $4.8 \mathrm{ab}$ & $4.5 \mathrm{a}$ & $3.8 \mathrm{a}$ & $2.8 \mathrm{ab}$ \\
$20 \%$ UYF & $5.0 \mathrm{a}$ & $5.0 \mathrm{a}$ & $4.7 \mathrm{a}$ & $4.2 \mathrm{a}$ & $3.2 \mathrm{a}$ \\
$5 \%$ FYF & $5.0 \mathrm{a}$ & $4.7 \mathrm{abc}$ & $4.2 \mathrm{a}$ & $2.8 \mathrm{c}$ & $2.0 \mathrm{de}$ \\
$10 \%$ FYF & $5.0 \mathrm{a}$ & $4.5 \mathrm{bcd}$ & $3.0 \mathrm{~b}$ & $2.8 \mathrm{c}$ & $2.5 \mathrm{cb}$ \\
$15 \%$ FYF & $5.0 \mathrm{a}$ & $4.3 \mathrm{~cd}$ & $3.3 \mathrm{~b}$ & $2.2 \mathrm{de}$ & $2.2 \mathrm{~cd}$ \\
$20 \%$ FYF & $5.0 \mathrm{a}$ & $4.2 \mathrm{~d}$ & $3.2 \mathrm{~b}$ & $1.8 \mathrm{e}$ & $2.0 \mathrm{de}$ \\
\hline
\end{tabular}

${ }^{\dagger}$ Values in the same column with the same letter are not statistically significant $(\mathrm{P}<0.05)$; RWF $=$ refined wheat flour, UYF = unfermented-white yam flour, FYF = fermented-brown yam flour 
tortillas. This observation was similar to the previous study, where it was stated that the rollability of refined wheat and whole wheat tortillas reduced as the duration of storage increased [5]. Likewise, in agreement with this report, the rollability of tortillas was stated to have reduced during storage, even with the addition of different hydrocolloids [38].

The decrease in rollability has been attributed to starch reorganization, where the adjacent linear chain of amylose or amylopectin form double helices via hydrogen bonding, and consequently aggregate to produce crystalline structures. The amylose was stated to change during storage and lead to the formation of increased order in the amylose structure [22]. This agrees with the work of Liu, et al. [39], who studied the viscoelastic and textural characteristics of tortilla from composite flour and reported a decrease in the rollability and pliability of tortillas with an increase in storage time. The type of wheat flour, the protein content, and quality are important attributes for making good quality tortillas [35]. High rollability scores in UYF tortillas can be associated with their high protein content, as observed in Table 1 . The $20 \%$ UYF blends with the highest wet gluten and gluten index, which signifies protein quality, may enhance tortilla storage stability, and decrease the breakage amount during rolling and handling of the stored tortillas. The higher moisture content of the UYF and FYF tortillas may have also contributed to the flexibility and better rollability of the tortillas.

\subsection{Effect of Storage on Resistance to Extension of Tortillas}

The ability of tortilla to resist tearing is also one of its essential characteristics and quality attributes. Figure 2 shows the changes in resistance to the extension of tortillas made from the flour samples during seven days of storage. There were significant $(\mathrm{P}<0.05)$ differences in the resistance to extension of tortillas.

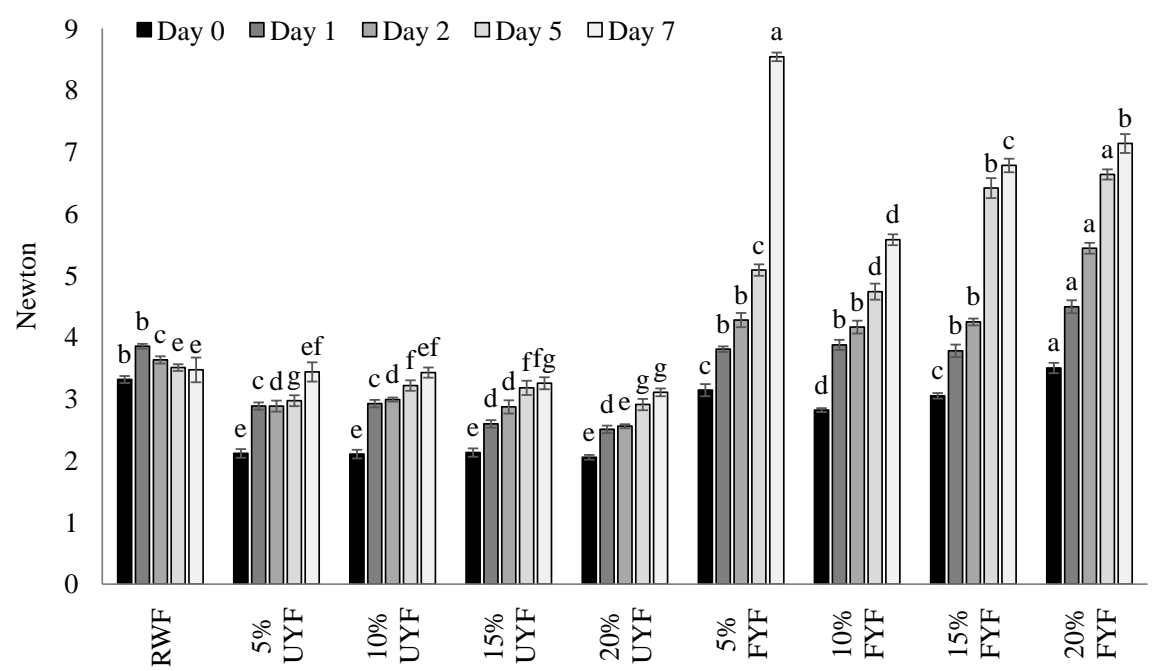

Figure 2. Resistance to extension (strength/toughness) of tortillas made from wheat/yam flour blends during seven days of storage. ${ }^{\star}$ Bars of the same color with the same letter are not statistically significant $(\mathrm{P}<0.05)$; RWF $=$ refined wheat flour, UYF $=$ unfermented-white yam flour, FYF = fermented-brown yam flour. 
On day zero, the RWF tortillas had significantly $(\mathrm{P}<0.05)$ higher resistance to extension than all UYF and FYF tortillas, except the $20 \%$ FYF tortillas. The decreased strength of the composite flour tortillas on day zero may be related to the dilution of the gluten proteins by the addition of the yam flours. The trend in changes to resistance to extension in tortillas made from RWF exhibited an initial increase after day one and then decreased through day seven. However, tortillas from composite flours increase in resistance to extension.

The rate of change in resistance to extension by tortillas from UYF blends is lesser than the rate of change in resistance to extension in that of FYF blends. The rate of change in resistance to extension in all tortillas made from UYF and FYF blends followed similar trends. During the day zero to day seven storage period, the change in resistance to extension in tortillas from FYF blends is pronounced in $5 \%$ FYF blend, followed by that of $20 \%$ FYF, then 15\% FYF, and then $10 \%$ FYF blends. The FYF blends exhibited a very high tortilla strength; hence, UYF is a better option between the composite-made-tortillas since very tough tortilla would be unsuitable as a wrapper or carrier for different fillings [40]. The resistance in extension may be affected by changes in the amylose content of the flour blends. The UYF and FYF flours in this study had 17.3 and 22.6 percent amylose, respectively [26]. While, the wheat flour would have approximately 25 percent amylose, which is typical for native wheat starches. It has been seen that tortillas with lower amylose have a higher increase in resistance to extension during storage [22]. Compared to FYF tortillas, the RWF and UYF tortillas have a more tender texture. Thus, the substitution of RWF with UYF will not alter the tenderness of tortillas.

\subsection{Effect of Storage on the Extensibility of Tortillas}

The extensibility/stretchiness of the flour tortillas is expressed as the distance between the beginning point of stretching and the point of tortilla rupture. The greater the distance at the point of rupture, the more stretchable the product, and the higher the force at the point of rupture, the stronger the product [41]. Flexibility is one of the most significant textural characteristics of the tortilla. A flexible tortilla will tolerate folding and rolling without cracking or breaking. Figure 3 shows the changes in the extensibility of tortillas made from RWF, FYF, and UYF blend samples during the seven days storage period. Significant $(\mathrm{P}<0.05)$ differences in the changes of the extensibility of tortillas were found. On day one, the substitution of RWF with $5 \%$ and $10 \%$ of yam flours caused a reduction in tortillas extensibility, while the increase in the level of substitution with yam flour caused an increase in tortillas extensibility.

Fresh tortillas are softer and more extensible than aged tortillas, an observation that is similar to previous work [39]. All tortillas samples exhibited decreased in their own extensibility throughout the storage period. The extensibility of tortillas made from composite flours containing higher concentrations of yam flours is comparable with that of the control. The decrease in crust softness 


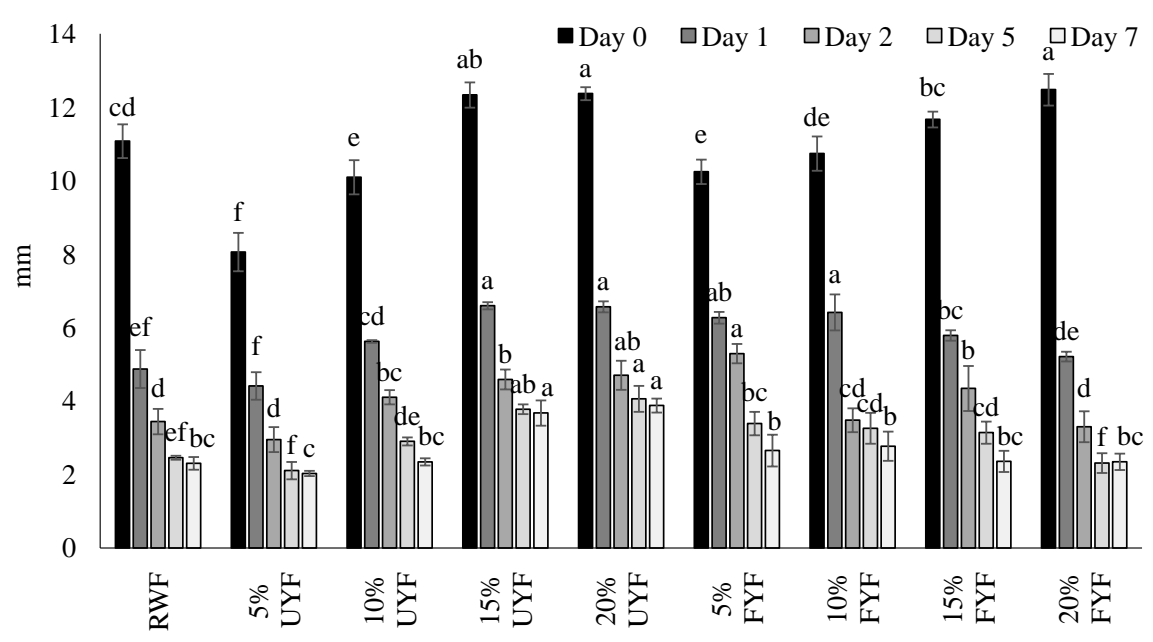

Figure 3. Extensibility of tortillas made from wheat/yam flour blends during seven days of storage. ${ }^{\star}$ Bars of the same color with the same letter are not statistically significant $(\mathrm{P}<$ 0.05); RWF $=$ refined wheat flour, UYF $=$ unfermented-white yam flour, FYF $=$ fermented-brown yam flour.

and crumb puffiness during storage might be attributed to the decline in flexibility [23]. The characteristics of flour have been reported to affect the extensibility of tortillas. Tortillas from the flours of different genotypes of spring wheat exhibited varying extensibility [22].

\section{Conclusion}

The substitution of wheat flour with fermented or unfermented yam flour (FYF or UYF) significantly affects the dough properties and physical characteristics of the tortilla. Consumer acceptance of tortillas prepared with FYF could be affected by the decrease in whiteness caused by the addition of the brown-colored FYF. The UYF tortillas were expected to be more resistant to retrogradation, and this was evident from the changes in tortilla texture during storage. The higher pasting temperature implies more energy needed for composite flour than wheat flour during the gelatinization process. The increased energy needed for starch gelatinization of the composite flours may affect tortilla processing and cooking times. Composite flour addition reduces stability, FQN, and increased MTI shows the low quality and weakened dough except for 5\% FYF, which exhibits no significant difference in the farinograph characteristics with that of control. Overall, this study has shown that the inclusion of $15 \%$ or $20 \%$ UYF with wheat flour would be suitable for making tortillas with excellent flexible texture.

\section{Authors' Contributions}

Conceptualization, SS; Methodology, TTAH, and SS; Formal Analysis, TTAH; Investigation, TTAH, and SS; Resources, SS; Data Curation, TTAH; Writing Original Draft Preparation, TTAH; Writing Review \& Editing, TTAH, and SS; Supervision, SS; Project Administration, SS; Funding Acquisition, SS. 


\section{Conflicts of Interest}

The authors declare no conflicts of interest regarding the publication of this paper.

\section{References}

[1] Serna-Saldivar, S.O., Perez-Carrillo, E. and Heredia-Olea, E. (2019) Soybean-Fortified Wheat Flour Tortillas. In: Flour and Breads and Their Fortification in Health and Disease Prevention, Elsevier, Amsterdam, 291-306. https://doi.org/10.1016/B978-0-12-814639-2.00023-X

[2] Kabbani, J. (2016) Tortilla Industry Overview. Proceedings of Tortilla Industry Association Technical Conference, Las Vegas, 7-8 October 2016, 1-46.

[3] Anton, A.A., Ross, K.A., Lukow, O.M., Fulcher, R.G. and Arntfield, S.D. (2008) Influence of Added Bean Flour (Phaseolus vulgaris L.) on Some Physical and Nutritional Properties of Wheat Flour Tortillas. Food Chemistry, 109, 33-41. https://doi.org/10.1016/j.foodchem.2007.12.005

[4] Pliego, R.G., Rodriguez, Y.M.V. and Olvera, N.G. (2019) Fermented Flour Nutraceutical Tortilla and Process for Preparation Thereof. Google Patents.

[5] Barros, F., Alviola, J. and Rooney, L. (2010) Comparison of Quality of Refined and Whole Wheat Tortillas. Journal of Cereal Science, 51, 50-56. https://doi.org/10.1016/j.jcs.2009.10.001

[6] Asiyanbi-Hammed, T.T. (2017) Characteristics of Yam Composite Flour: Properties and Function of Bread and Tortilla Making. North Dakota State University, Fargo.

[7] Amandikwa, C., Iwe, M., Uzomah, A. and Olawuni, A. (2015) Physico-Chemical Properties of Wheat-Yam Flour Composite Bread. Nigerian Food Journal, 33, 12-17. https://doi.org/10.1016/j.nifoj.2015.04.011

[8] Adebowale, A.-R.A., Wahab, A.B., Sobukola, P.O., Obadina, A.O., Kajihausa, E.O., Adegunwa, O.M., Sanni, O.L. and Tomlins, K. (2018) The Antinutritional and Vitamin Composition of High-Quality Yam Flour as Affected by Yam Specie, Pretreatment, and Drying Method. Food Science \& Nutrition, 6, 1985-1990.

https://doi.org/10.1002/fsn3.619

[9] Achi, O. and Akubor, P. (2000) Microbiological Characterization of Yam Fermentation for "Elubo" (Yam Flour) Production. World Journal of Microbiology and Biotechnology, 16, 3-7. https://doi.org/10.1023/A:1008980912708

[10] Lye, T.Y. (2018) Enhancement of Fiber Value in Wheat Flour Tortilla Using Guava Fruit (Psidium guajava var. Pyrifera). Tunku Abdul Rahman University College.

[11] Heredia-Olea, E., Martínez-Martínez, A., Payan-Tamez, S., Palomera-Santandreu, I., Guajardo-Flores, S. and Pérez-Carrillo, E. (2015) Effect of Inuline and Oatmeal Addition on Fat and Dietary Fiber Content in Hot Press Wheat Flour Tortilla. Journal of Food Research, 4, 44-50. https://doi.org/10.5539/jfr.v4n2p44

[12] Bugusu, B.A., Campanella, O. and Hamaker, B.R. (2001) Improvement of Sorghum-Wheat Composite Dough Rheological Properties and Breadmaking Quality through Zein Addition. Cereal Chemistry, 78, 31-35.

https://doi.org/10.1094/CCHEM.2001.78.1.31

[13] Sun, K.-N., Liao, A.-M., Zhang, F., Thakur, K., Zhang, J.-G., Huang, J.-H. and Wei, Z.-J. (2019) Microstructural, Textural, Sensory Properties and Quality of Wheat-Yam Composite Flour Noodles. Foods, 8, 519. https://doi.org/10.3390/foods8100519

[14] Raymond, J., Afranaa, K., Festus, N. and Oluwole, F. (2018) Biomass-Based Innova- 
tions in Demand Driven Research and Development Projects in Africa. Sustainability, 10, 2639. https://doi.org/10.3390/su10082639

[15] Aristizábal, J., García, J.A. and Ospina, B. (2017) Refined Cassava Flour in Bread Making: A Review. Ingeniería e Investigación, 37, 25-33. https://doi.org/10.15446/ing.investig.v37n1.57306

[16] Noorfarahzilah, M., Lee, J.S., Sharifudin, M., Mohd Fadzelly, A. and Hasmadi, M. (2014) Applications of Composite Flour in Development of Food Products. International Food Research Journal, 21, 2061-2074.

[17] Falade, K., Olapade, A. and Abdul, K. (2012) Comparative Performances of Composite Flours from Blends of Yam (Dioscorea rotundata), Cassava (Manihot esculenta Crantz) and Wheat Flours in Cake Preparation. Journal of Agricultural Research and Development, 11, 290-294.

[18] Ranaivosoaa, B., Jeannodac, D.V.V. and Razanamparanya, J. (2009) Effects of Age and Geographical Origin in Global Preference of Consumers of Yam Tubers and Mix Wheat Yam Flours Cookies. Proceedings of Food Consumer Insights in Asia: Current Issues and Future, Proceedings of SPISE, Ho Chi Minh City, 70-77.

[19] Jung, D.-S., Lee, F.-Z. and Eun, J.-B. (2002) Quality Properties of Bread Made of Wheat Flour and Black Rice Flour. Korean Journal of Food Science and Technology, 34, 232-237.

[20] Oluwamukomi, M., Oluwalana, I. and Akinbowale, O. (2011) Physicochemical and Sensory Properties of Wheat-Cassava Composite Biscuit Enriched with Soy Flour. African Journal of Food Science, 5, 50-56.

[21] AACC-I (2009) AACC International Approved Methods of Analysis.

[22] Whitney, K., Simsek, S., Berzonsky, W., OHM, J.B. and Sorenson, B. (2011) The Effect of Spring Wheat Starch Properties on Flour Tortilla Quality. Journal of Food Process Engineering, 34, 697-715. https://doi.org/10.1111/j.1745-4530.2009.00428.x

[23] Bello, A., SO, S.S., Waniska, R. and Rooney, L. (1991) Methods to Prepare and Evaluate Wheat Tortillas. Cereal Foods World, 36, 315-322.

[24] Kelekci, N., Pascut, S. and Waniska, R. (2003) The Effects of Storage Temperature on the Staling of Wheat Flour Tortillas. Journal of Cereal Science, 37, 377-380. https://doi.org/10.1006/jcrs.2002.0509

[25] Suhendro, E., Almeida-Dominguez, H., Rooney, L., Waniska, R. and Moreira, R. (1999) Use of Extensibility to Measure Corn Tortilla Texture. Cereal Chemistry, 76, 536-540. https://doi.org/10.1094/CCHEM.1999.76.4.536

[26] Asiyanbi-Hammed, T.T. and Simsek, S. (2018) Comparison of Physical and Chemical Properties of Wheat Flour, Fermented Yam Flour, and Unfermented Yam Flour. Journal of Food Processing and Preservation, 42, e13844. https://doi.org/10.1111/jfpp.13844

[27] Pascut, S., Kelekci, N. and Waniska, R. (2004) Effects of Wheat Protein Fractions on Flour Tortilla Quality. Cereal Chemistry, 81, 38-43. https://doi.org/10.1094/CCHEM.2004.81.1.38

[28] Mestres, C., Dorthe, S., Akissoé, N. and Hounhouigan, J.D. (2004) Prediction of Sensorial Properties (Color and Taste) of Amala, a Paste from Yam Chips Flour of West Africa, through Flour Biochemical Properties. Plant Foods for Human Nutrition, 59, 93-99. https://doi.org/10.1007/s11130-004-0028-z

[29] Akissoé, N., Hounhouigan, J., Mestres, C. and Nago, M. (2003) How Blanching and Drying Affect the Colour and Functional Characteristics of Yam (Dioscorea cayenensis-rotundata) Flour. Food Chemistry, 82, 257-264. 
https://doi.org/10.1016/S0308-8146(02)00546-0

[30] Oates, C.G. (2018) Bread Microstructure. In: Bread Staling, CRC Press, Boca Raton, 149-162. https://doi.org/10.1201/9781351070348-8

[31] Zheng, X. and Wang, S.S. (1994) Shear Induced Starch Conversion during Extrusion. Journal of Food Science, 59, 1137-1143. https://doi.org/10.1111/j.1365-2621.1994.tb08210.x

[32] Goldstein, A., Ashrafi, L. and Seetharaman, K. (2010) Effects of Cellulosic Fibre on Physical and Rheological Properties of Starch, Gluten and Wheat Flour. International Journal of Food Science \& Technology, 45, 1641-1646. https://doi.org/10.1111/j.1365-2621.2010.02323.x

[33] Zhou, Y., Zhao, D., Winkworth-Smith, C.G., Foster, T.J., Nirasawa, S., Tatsumi, E. and Cheng, Y. (2015) Effect of a Small Amount of Sodium Carbonate on Konjac Glucomannan-Induced Changes in Wheat Starch Gel. Carbohydrate Polymers, 116, 182-188. https://doi.org/10.1016/j.carbpol.2014.02.087

[34] Sapirstein, H., Wu, Y., Koksel, F. and Graf, R. (2018) A Study of Factors Influencing the Water Absorption Capacity of Canadian Hard Red Winter Wheat Flour. Journal of Cereal Science, 81, 52-59. https://doi.org/10.1016/j.jcs.2018.01.012

[35] Waniska, R. (1999) Perspectives on Flour Tortillas. Cereal Foods World, 44, 471-473.

[36] Brooker, D. (2010) Tortilla Tips: Moisture Content of Tortillas. https://www.tortillanews.com/2010/04/tortilla-tips-moisture-content-of-tortillas

[37] Bejosano, F.P., Joseph, S., Lopez, R.M., Kelekci, N.N. and Waniska, R.D. (2005) Rheological and Sensory Evaluation of Wheat Flour Tortillas during Storage. Cereal Chemistry, 82, 256-263. https://doi.org/10.1094/CC-82-0256

[38] Friend, C.P., Waniska, R.D. and Rooney, L.W. (1993) Effects of Hydrocolloids on Processing and Qualities of Wheat Tortillas. Cereal Chemistry, 70, 252-252.

[39] Liu, T., Hou, G.G., Cardin, M., Marquart, L. and Dubat, A. (2017) Quality Attributes of Whole-Wheat Flour Tortillas with Sprouted Whole-Wheat Flour Substitution. LWT, 77, 1-7. https://doi.org/10.1016/j.lwt.2016.11.017

[40] Ramírez-Wong, B., Walker, C., Ledesma-Osuna, A.I., Torres, P.I., Medina-Rodríguez, C.L., López-Ahumada, G.A., Salazar-García, M.G., Ortega-Ramírez, R., Johnson, A. and Flores, R.A. (2007) Effect of Flour Extraction Rate on White and Red Winter Wheat Flour Compositions and Tortilla Texture. Cereal Chemistry, 84, 207-213. https://doi.org/10.1094/CCHEM-84-3-0207

[41] Mao, Y., Flores, R.A. and Loughin, T.M. (2002) Objective Texture Measurements of Commercial Wheat Flour Tortillas. Cereal Chemistry, 79, 648-653.

https://doi.org/10.1094/CCHEM.2002.79.5.648 


\section{Graphical Abstract}

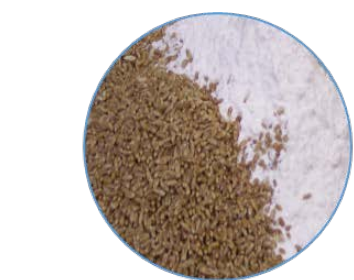

Hard Red Spring Wheat Flour

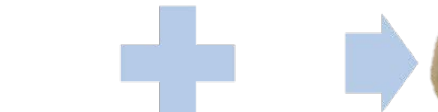

Yam (Dioscorea sp.) Flour

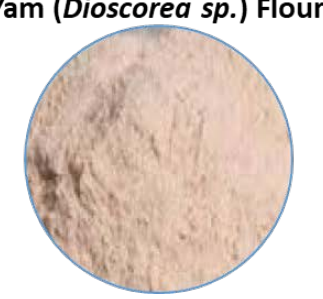

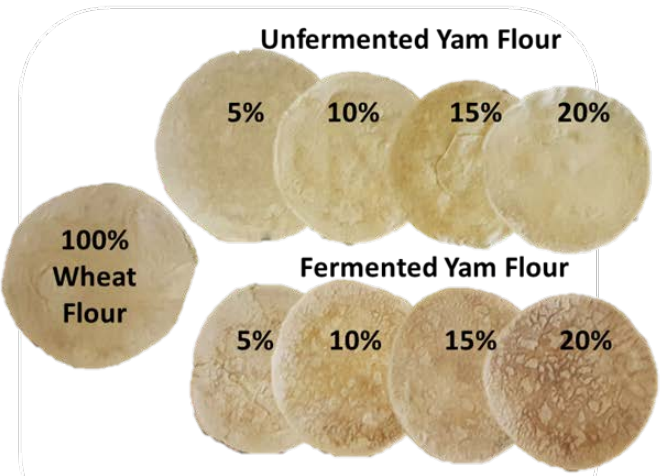

